\title{
A INFLUÊNCIA DO PERFIL EMPREENDEDOR NO DESEMPENHO DO NEGÓCIO EM UMA REDE DE FRANQUIA DE CONFEÇÃO INFANTIL
}

\author{
Caio Júlio de Souza Fontenelle ${ }^{1}$ \\ Marianne Hoeltgebaum²
}

\begin{abstract}
Resumo: Este estudo objetiva identificar as principais características comportamentais empreendedoras dos proprietários de franquia de uma rede de confecção infantil e verificar se a presença das características empreendedoras nos franqueados influencia no resultado alcançado nas empresas. Foram coletadas informações sobre o desempenho das empresas e selecionado um instrumento de mensuração de desempenho dos franqueados, com o intuito de identificar as principais características comportamentais empreendedoras dos proprietários de franquia de confecção infantil, conforme seu desempenho. Neste trabalho pressupõe-se que as características que identificam um empreendedor, se presentes em um franqueado, podem diferenciá-lo em resultado perante as demais franquias. Esta pesquisa é do tipo descritiva e quantitativa e foi aplicada nas franquias de confecção infantil pertencentes a uma mesma rede, distribuídas pelo território nacional brasileiro. Neste estudo concluiu-se que existe uma relação entre um desempenho superior e a presença de características empreendedoras nos franqueados avaliados. Sendo assim, confirma-se a importância de tais características para o sucesso de um empreendimento.
\end{abstract}

Palavras-chave: empreendedorismo, características comportamentais, franquias.

\section{INTRODUÇÃO}

Na busca do sucesso de seu negócio, muitos empreendedores vêm buscando aplicar modelos de negócio já consagrados, como, por exemplo, o modelo aplicado pelas franquias. Porém, apesar das franquias já possuírem um modelo de gestão administrativo e de produto já comprovado, isto não significa que todo franqueado de uma rede alcance o sucesso almejado seguindo o manual fornecido pelo franqueador. Dentro de uma rede de franquia, encontram-se performances bastante distintas entre seus franqueados, existindo operações extremamente lucrativas, como, também, operações deficitárias,

\footnotetext{
${ }^{1}$ Universidade Regional de Blumenau- FURB. E-Mail: caiobia@terra.com.br

${ }^{2}$ Departamento de Administração e Programa de Pós Graduação em Administração pela Universidade Regional de Blumenau- FURB. E-Mail: marianne@furb.br
} 
em mercados com potencial e características muito semelhantes. Os empreendedores possuem um papel importante no desempenho de um negócio. Suas características pessoais e profissionais alteram o resultado obtido e o próprio crescimento da empresa. De acordo com Gerber (1996), a personalidade empreendedora transforma a condição mais insignificante numa excepcional oportunidade. É um inovador, estrategista, criador de novos métodos para entrar em mercados já existentes ou criar novos.

Com este estudo objetiva-se estabelecer a relação das principais características empreendedoras que o franqueado deve possuir para promover o melhor desempenho do negócio. Assim, por meio de uma pesquisa junto a um grupo de empresários de uma franquia de confecção infantil, procurou-se identificar as características comportamentais do empreendedor, presente nos empresários com melhor desempenho.

\section{FUNDAMENTAÇÃO TEÓRICA}

\subsection{EMPREENDEDORISMO}

\subsubsection{O empreendedor}

O universo do empreendedorismo é dotado de uma pequena confusão sobre a definição do que é empreendedor. Filion (1999, p. 6) explica que esta confusão ocorre porque "os pesquisadores tendem a perceber e definir empreendedores usando premissas de suas próprias disciplinas.". Existe uma definição por parte dos economistas, associando o empreendedor com a inovação, enquanto os comportamentalistas (psicólogos, psicanalistas, sociólogos) associam o empreendedor a aspectos criativos e intuitivos. Inicialmente apenas os economistas descreveram o empreendedor, entretanto não conseguiram inserir elementos racionais, característica da ciência econômica, para explicar e entender o complexo comportamento do empreendedor. Esta dificuldade possibilitou aos pesquisadores comportamentalistas buscar um conhecimento mais profundo do comportamento do empreendedor. Max Weber foi um dos primeiros autores a discorrer sobre o comportamento do empreendedor por meio de um sistema de valores. Entretanto foi David C. McClelland que deu início a maior contribuição da ciência do comportamento para o empreendedorismo. Depois de McClelland outros comportamentalistas contribuíram para definir o que são empreendedores e as suas características (FILION, 1999). McClelland (1972), descreve os empreendedores como indivíduos que, por possuir um certo arrojo em suas atitudes, conseguem transformar a realidade. Esses indivíduos, que são poucos, possuem características especificas, que os diferencia dos demais.

O termo empreendedor tem origem francesa (entrepreneur) e significa, segundo Drucker (1991), aquele que assume risco e começa algo novo. Foi utilizado pela primeira vez por volta de 1800, por Jean-Baptiste Say - economista francês - com o intuito de distinguir o indivíduo que consegue transferir recursos econômicos de um setor com baixa produtividade para um setor com produtividade elevada e com maiores rendimentos. Joseph Schumpeter, no século XIX, dá nova conotação ao termo empreendedor, definindoo como alguém que perturbava e desorganizava a ordem vigente, sendo o agente 
responsável pela transformação e desenvolvimento econômico. Para ele, empreendedor é alguém que faz novas combinações de elementos, introduzindo novos processos ou produtos, identificando novos mercados de exportação ou fontes de suprimentos, criando novos tipos de organizações (LONGEN, 1997). Kuratko (1989) salienta que o empreendedor exerce o papel de um catalisador para as mudanças que ocorrem no mundo dos negócios. Que o empreendedor é um pensador independente e ousa ser diferente dentro de um ambiente cercado por acontecimentos comuns. Ele tem a capacidade de acompanhar, controlar ou até mesmo ajustar os resultados que cada principal influência exerce sobre o seu empreendimento.

Acredita-se hoje que o empreendedor seja o 'motor da economia', um agente de mudanças. Muito se tem escrito a respeito, e a literatura oferece variadas definições para o termo. Filion (1999, p. 19) define empreendedor como "[...] a pessoa que imagina, desenvolve e realiza visões.". Farrel (1993, p. 27) justifica a importância do empreendedor para a economia, demonstrando que as verdadeiras causas do crescimento de algumas empresas é o espírito empreendedor, "é ele que constrói empresas.". Dolabela (2002) diz que o empreendedor é um ser social, produto do meio em que vive. Se uma pessoa vive em um ambiente em que ser empreendedor é visto como algo positivo, então terá motivação para criar o seu próprio negócio. Longenecker et al (1997, p. 3) procuram dar um tom mais romântico a esses empresários, dizendo que "os empreendedores são os heróis populares da moderna vida empresarial." Isso porque eles fornecem empregos, introduzem inovações e estimulam o crescimento econômico. Já não são vistos como provedores de mercadorias nada interessantes. Em vez disso, eles são vistos como energizadores que assumem riscos necessários em uma economia em crescimento, produtiva. A cada ano, milhares de indivíduos desse tipo, de adolescentes a cidadãos mais velhos, inauguram novos negócios por conta própria e assim fornecerem a liderança dinâmica que leva ao progresso econômico.

\subsubsection{Características comportamentais do empreendedor}

Historicamente, os empreendedores têm sido um espécime à parte em relação ao estereótipo do homem de negócios. "Eles eram determinados, inovadores, ousados iconoclastas que prezam sua independência." (ZOGHLIN, 1994, p. 3). Alguns dos mais conhecidos empreendedores, Henry Ford ${ }^{1}$, por exemplo, eram capazes de ser implacáveis. Eles não hesitavam em modificar ou passar por cima das regras para conseguir o que queriam. Os executivos, ao contrário, seguiam as regras empresariais mecanicamente: era cômodo trabalhar para uma grande organização, numa época em que os empregos eram para a vida toda.

Degen (1989) descreve o empreendedor como sendo uma pessoa com necessidade de realizar coisas novas, com disposição para assumir risco. Predisposição para identificar oportunidades e grande criatividade. Para Farrel (1993), o empreendedor precisa ter algumas características fundamentais para o sucesso do seu empreendimento. É importantíssimo conhecer o seu produto e o mercado como ninguém, permitindo assim estar à frente dos concorrentes. Saber conduzir as pessoas e incentivá-las a fazer bem feito. É imprescindível ter o foco constante no produto e no cliente, como também a capacidade de estabelecer os valores ou crenças das pessoas em sua empresa. "Um empreendedor é uma pessoa que imagina, desenvolve e realiza visões.", Filion (1999, p. 19) assim o resume. Ser criativo, gostar de estabelecer e atingir objetivos, enxergar oportunidades por meio de um alto nível de consciência do ambiente que vive. Continuar a aprender, viver em constante 
evolução, tomar decisões e inovar sempre são as principais características do empreendedor. Para Kuratko (1989) existe algumas similaridades nos estudos sobre o empreendedor, no entanto, salienta as características mais importantes em um empreendedor. No quadro 2 é realizado um apanhado das principais características compartimentais de um empreendedor sob a abordagem de vários autores.

\begin{tabular}{|c|c|c|c|}
\hline Azevedo & Berbel & McClelland & Zoghlin \\
\hline 1. Capacidade de & 1. Disposição $\mathrm{p} /$ & $\begin{array}{l}\text { 1. Busca de } \\
\text { oportunidades }\end{array}$ & 1. Determinados; \\
\hline assumir riscos; & assumir riscos; & e iniciativa; & 2. Inovadores; \\
\hline 2. Capacidade de & 2. Ter iniciativa $\mathrm{e}$ & 2. Persistência; & 3. Ousados; \\
\hline $\begin{array}{l}\text { identificar } \\
\text { oportunidades; }\end{array}$ & ser independente; & 3. Comportamento; & 4. Iconoclastas, que \\
\hline $\begin{array}{l}\text { 3. Conhecimento do } \\
\text { ramo; }\end{array}$ & 3. Ser líder e saber & $\begin{array}{l}\text { 4. Exigência de } \\
\text { qualidade }\end{array}$ & $\begin{array}{l}\text { prezam sua } \\
\text { independência; }\end{array}$ \\
\hline $\begin{array}{l}\text { 4. Senso de } \\
\text { organização; }\end{array}$ & comunicar-se; & e eficiência; & 5. Implacáveis; \\
\hline 5. Disposição para & 4. Ser organizado; & 5. Assumir riscos & 6. Assume riscos; \\
\hline tomar decisão; & $\begin{array}{l}\text { 5. Possuir } \\
\text { conhecimento }\end{array}$ & calculados; & $\begin{array}{l}\text { 7. Habilidade para } \\
\text { lidar }\end{array}$ \\
\hline 6. Habilidade de & no ramo; & $\begin{array}{l}\text { 6. Determinação de } \\
\text { metas; }\end{array}$ & $\begin{array}{l}\text { com o futuro } \\
\text { incerto; }\end{array}$ \\
\hline liderar; & 6. Identificador de & $\begin{array}{l}\text { 7. Busca de } \\
\text { informações; }\end{array}$ & 8. Capacidade de se \\
\hline 7. Talento para & oportunidades; & 8. Planejamento e & auto motivar; \\
\hline empreender; & 7. Possuir aptidões & $\begin{array}{l}\text { monitoramento } \\
\text { sistemático; }\end{array}$ & 9. Capacidade de \\
\hline 8. Independência & empresariais; & 9. Persuasão e rede & trabalhar sozinho; \\
\hline pessoal; & 8. Auto conhecimento; & de contatos; & $\begin{array}{l}\text { 10. Tomada de } \\
\text { decisão; }\end{array}$ \\
\hline 9. Otimismo; & 9. Manter o otimismo. & 10. Independência e & 11. Disciplina. \\
\hline $\begin{array}{l}\text { 10. Tino } \\
\text { empresarial. }\end{array}$ & & autoconfiança. & \\
\hline Longenecker et al & $\begin{array}{l}\text { Iverson e Litter apud } \\
\text { Riscarolli }\end{array}$ & Leite & Fucs e Osman \\
\hline 1. Necessidade de & $\begin{array}{l}\text { 1. Paciência e } \\
\text { perseverança; }\end{array}$ & $\begin{array}{l}\text { 1. Coeficiente de } \\
\text { sociabilidade; }\end{array}$ & $\begin{array}{l}\text { 1. Capacidade de } \\
\text { sonhar; }\end{array}$ \\
\hline realização; & $\begin{array}{l}\text { 2. Economia e } \\
\text { habilidade em }\end{array}$ & 2. Liderança; & $\begin{array}{l}\text { 2. Paixão pelo que } \\
\text { faz; }\end{array}$ \\
\hline 2. Disposição para & gerenciar dinheiro; & 3. Segurança; & 3. Iniciativa; \\
\hline $\begin{array}{l}\text { assumir riscos } \\
\text { moderados; }\end{array}$ & 3. Flexibilidade; & 4. Comando; & 4. Criatividade; \\
\hline $\begin{array}{l}\text { 3. Forte } \\
\text { autoconfiança; }\end{array}$ & 4. Trabalho duro; & $\begin{array}{l}\text { 5. Despertar iniciativa } \\
\text { no pessoal; }\end{array}$ & 5. Curiosidade; \\
\hline
\end{tabular}




\begin{tabular}{|c|c|c|c|}
\hline Oliveira & Dornellas & Dolabela & Timonns \\
\hline 1. Ter visão; & 1. São visionários; & 1. Possui um "modelo" & $\begin{array}{l}\text { 1. } \\
\text { Comprometimento, } \\
\text { determinação }\end{array}$ \\
\hline $\begin{array}{l}\text { 2. Capacidade de } \\
\text { enxergar }\end{array}$ & $\begin{array}{l}\text { 2. Sabem tomar } \\
\text { decisão; }\end{array}$ & $\begin{array}{l}\text { uma pessoa que } \\
\text { influencia; }\end{array}$ & e perseverança; \\
\hline oportunidades; & 3. São indivíduos que & $\begin{array}{l}\text { 2. Iniciativa, } \\
\text { autonomia, otimismo, }\end{array}$ & $\begin{array}{l}\text { 2. Busca auto- } \\
\text { realização, cresci }\end{array}$ \\
\hline $\begin{array}{l}\text { 3. Insight e visão: } \\
\text { capacidade }\end{array}$ & fazem a diferença; & $\begin{array}{l}\text { autoconfiança, } \\
\text { necessidade de }\end{array}$ & $\begin{array}{l}\text { mento com metas } \\
\text { desafiadoras; }\end{array}$ \\
\hline $\begin{array}{l}\text { de descobrir novas } \\
\text { idéias; }\end{array}$ & 4. Sabem explorar ao & realização; & $\begin{array}{l}\text { 3. Senso de } \\
\text { oportunidade e }\end{array}$ \\
\hline $\begin{array}{l}\text { 4. "Serendipitia" e } \\
\text { visão: }\end{array}$ & $\begin{array}{l}\text { máximo as } \\
\text { oportunidades; }\end{array}$ & 3. Trabalha sozinho; & $\begin{array}{l}\text { orientação para } \\
\text { metas; }\end{array}$ \\
\hline $\begin{array}{l}\text { capacidade de } \\
\text { descobrir alguma }\end{array}$ & 5. São determinados e & $\begin{array}{l}\text { 4. Perseverança e } \\
\text { tenacidade; }\end{array}$ & $\begin{array}{l}\text { 4. Iniciativa pelo } \\
\text { senso de }\end{array}$ \\
\hline $\begin{array}{l}\text { coisa, quando se } \\
\text { estava }\end{array}$ & dinâmicos; & $\begin{array}{l}\text { 5. Aprende com os } \\
\text { erros; }\end{array}$ & $\begin{array}{l}\text { responsabilidade } \\
\text { social; }\end{array}$ \\
\hline procurando outra; & 6. São dedicados; & $\begin{array}{l}\text { 6. Grande energia, é } \\
\text { incansável; }\end{array}$ & $\begin{array}{l}\text { 5. Persistência e } \\
\text { determinação }\end{array}$ \\
\hline $\begin{array}{l}\text { 5. Visão } \\
\text { sistematizada }\end{array}$ & 7. São otimistas e & $\begin{array}{l}\text { 7. Fixar metas e } \\
\text { alcançá-las; }\end{array}$ & $\begin{array}{l}\text { na resolução de } \\
\text { problemas; }\end{array}$ \\
\hline negocio; & apaixonados pelo & descobrir nichos; & $\begin{array}{l}\text { 6. Entram situações } \\
\text { adversas com }\end{array}$ \\
\hline $\begin{array}{l}\text { 6. "Expertise": } \\
\text { conhecimento }\end{array}$ & que fazem; & 8. Forte intuição; & $\begin{array}{l}\text { otimismo, humor e } \\
\text { perspectiva; }\end{array}$ \\
\hline $\begin{array}{l}\text { do ramo que } \\
\text { empreenderá; }\end{array}$ & 8. São independentes & 9. Comprometimento; & $\begin{array}{l}\text { 7. Busca feedback } \\
\text { do desempenho }\end{array}$ \\
\hline $\begin{array}{l}\text { 7. Paixão pelo } \\
\text { trabalho; }\end{array}$ & e constroem o próprio & 10. Obtém feedback; & $\begin{array}{l}\text { e aprende com os } \\
\text { erros; }\end{array}$ \\
\hline gostar do que faz; & destino; & 11. Busca, controla e & $\begin{array}{l}\text { 8. Controle racional } \\
\text { do impulsos; }\end{array}$ \\
\hline 8. Ambição e gosto & 9. Ficam ricos; & utiliza recursos; & $\begin{array}{l}\text { 9. Encaram as } \\
\text { adversidades com }\end{array}$ \\
\hline pelo desafio; & 10. São lideres & 12. Sonhador realista; & naturalidade; \\
\hline
\end{tabular}

\section{Quadro 1: Resumo das principais características do empreendedor de diferentes} autores.

Fonte: próprio autor/pesquisador.

A iniciativa pessoal, a habilidade em consolidar recursos, habilidades gerenciais, desejo por autonomia e a capacidade de assumir riscos são comuns entre os autores. Outras características não menos importantes são agressividade, competitividade, comportamento orientado para objetivos, confiança, intuitividade, capacidade de aprender com os erros e habilidade nas relações humanas. A tese de que o empreendedor é fruto de herança genética não encontra mais seguidores nos meios científicos. Dolabela (2002, p. 28) finaliza essa teoria dizendo: "assim, é possível que as pessoas aprendam a ser empreendedoras, mas dentro de um sistema de aprendizagem especial bastante diferente do ensino tradicional.". 


\subsection{O SISTEMA DE FRANQUIA}

O empreendedor que compra uma franquia elimina etapas à medida que pode trabalhar com uma marca já testada no mercado, de qualidade e aceitação comprovadas. Isto implica que, na maioria dos casos, o franqueador não precisa ter conhecimentos prévios de como administrar o negócio em questão. Ao candidato a futuro empreendedor, que ainda não se decidiu, ou não está motivado a criar um negócio próprio independente nem a abrir uma microempresa terceirizada, Leite (1998), recomenda o sistema de franquia ${ }^{2}$ que, segundo ele, parece adequado àqueles executivos que ainda receiam se lançar no mundo empresarial.

Segundo Schneider (1991), o franqueado, por sua vez, terá o apoio de uma marca estabelecida, além da orientação, treinamento e supervisão oferecidos pelo franqueador, evitando, com isso, maiores gastos decorrentes da inexperiência na condução de um negócio. Em contrapartida, se submeterá às regras do sistema, perdendo, assim, a independência que teria com um negócio próprio. $\mathrm{O}$ franqueado se sujeita ainda às falhas do sistema, cujo controle está, principalmente, nas mãos do franqueador e também nas dos outros franqueados. Kanitz (1994, p. 69) diz que "a franquia traz um efeito fantástico no desenvolvimento do espírito empreendedor, [...] e dissemina técnicas gerenciais modernas entre a população em geral.". Schneider (1991) ensina que o sistema de franquias permite a criação de novos negócios próprios com maior segurança, pois a aplicação prática dos conceitos do sistema de negócio formatado e os estudos de viabilidade econômica e financeira torna a franquia ainda a alternativa mais viável para aqueles que possuem espírito empreendedor e queiram tornar-se independentes, mas não conhecem o ramo de negócios profundamente.Segundo Kanitz (1994, p. 71) "a franquia vai exercer uma função que a universidade (brasileira) não consegue mais cumprir, que é treinar pequenos empreendedores e bons gerentes [...]".

\subsection{CRITÉRIOS DE AVALIAÇÃO DE DESEMPENHO}

Definir objetivos e metas antecipadamente representa buscar muitas informações e de certa forma prever o futuro. Sá (1969) afirma que prever não pode, e não deve, ser um exercício de adivinhação, mas um processo organizado. Desta forma os diversos índices de avaliação de desempenho, que são informações, contribuirão para a elaboração das metas das empresas. Este conjunto de informações subsidiará os planos estratégicos e táticos da empresa. Parente (2000) relata os principais critérios para avaliar a performance de uma empresa de varejo e o atingimento dos seus objetivos estabelecidos. Estes critérios podem ser agrupados por afinidade de áreas ou atividades. Parente (2002) apresenta os seguintes critérios para identificar produtividade e eficiência:

- vendas por metro quadrado: é a capacidade que cada metro quadrado possui para atrair clientes;

- vendas por metro linear de prateleira: é a capacidade que cada metro linear de prateleira tem em converter venda;

- vendas por funcionários: mede a produtividade do funcionário;

- volume de vendas: mede o aumento ou diminuição do volume total das vendas;

- número de clientes: analisa o numero de clientes que visitam a loja; 
- venda média por tíquete: mensura o gasto de um cliente durante uma visita a loja;

- venda por atendimento: mede a venda em valor ou em peças por cliente atendido;

Os indicadores de desempenho utilizados pela rede estudada neste trabalho são disponibilizados no site oficial do franqueador. Cada empresa franqueada possui seu código de acesso permitindo verificar on-line o seu desempenho e atendimento de suas metas. Os indicadores de desempenho disponíveis no site são vários, abrangendo uma parte dos indicadores apontados pela literatura. As empresas franqueadas podem analisar a qualquer momento seus índices de: faturamento por loja, faturamento por metro quadrado, peças vendidas por um determinado período, peças por atendimento, preço médio, tíquete médio, vendas por vendedor e vendas $\mathrm{x}$ estoque.

\subsection{VANTAGENS E DESVANTAGENS DO MODELO DE MENSURAÇÃO ESCOLHIDO}

Para este estudo foram escolhidos quatro índices de mensuração desempenho de franqueados:

- meta de faturamento - este índice é utilizado pela franqueadora para verificar se a franquia está atingindo o potencial de mercado disponível em sua praça de atuação. As metas são elaboradas pela franqueadora, que se utiliza de parâmetros como IPME (Índice de Potencial de Mercado), histórico de vendas da marca anterior à implantação da franquia, histórico de vendas de outras marcas pertencentes à mesma empresa e informações da concorrência, para definição. As metas de faturamento são importantes à medida que isolam os fatores exógenos de mercado. Cada franquia pertencente à rede possui uma meta específica para a sua praça de atuação. Desta forma a franqueadora pode monitorar sua distribuição no mercado, verificando as necessidades de ampliação ou manutenção das vendas em cada região do país, podendo assim formular ações pontuais de marketing para recuperação ou ocupação de mercado.

- faturamento por metro quadrado - este tipo de mensuração de desempenho foi escolhido principalmente pela possibilidade comparativa entre as lojas da rede, pois desta forma, independente do tamanho ou formato da loja, pode-se fazer uma comparação com uma mesma unidade de medida. Este índice pode ser escolhido também porque não existem grandes diferenças nos tamanhos de loja, pois se trata de um projeto de arquitetura padrão, tendo as lojas em média sessenta metros quadrados.

- peças por atendimento - este é um índice de desempenho utilizado pela franqueadora para mensurar a produtividade da equipe de vendas da franquia. $\mathrm{O}$ índice é calculado somando-se todas as peças vendidas no período e dividindo-se pelo número de atendimentos de vendas. O índice também é bastante válido, pois permite uma comparação em uma mesma base com outras lojas da rede.

- valor por atendimento - este índice de desempenho é utilizado em conjunto com o de peças por atendimento. Também tem como propósito indicar a produtividade da equipe de vendas, no sentido de verificar se as vendedoras não estão vendendo somente peças de baixo valor agregado, como por exemplo meias. Se este for o caso a vendedora terá um alto índice em peças por atendimento e um baixo valor por atendimento, o que não deverá gerar um bom faturamento para a loja. 
Avaliando-se então, os índices de desempenho escolhidos para mensuração do trabalho, pode-se dizer que estão adequados aos objetivos, pois consideram o desempenho do franqueado perante as expectativas da franqueadora e o mercado, como também, sua produtividade comercial na gestão do negócio. Para determinar quais indicadores serão utilizados para comparar o desempenho das empresas franqueadas, foi tomado o cuidado de selecionar indicadores que permitissem isolar, um pouco, as influências das características do mercado local, onde a loja está instalada, as características da localização da loja (em shopping center ou loja de rua) e o porte do shopping center. Desta forma é possível obter uma unidade comparativa de comportamento, isolando de certa forma, as interferências do mercado de atuação da empresa franqueada.

\subsubsection{Características comportamentais}

Para avaliar as características comportamentais dos proprietários de franquias, foi escolhido um questionário desenvolvido por McClelland (1992) para avaliação das CCEs. Esta escolha foi baseada pela experiência do autor no assunto empreendedorismo e pela grande utilização que já foi feita deste instrumento de coleta de dados em estudos científicos já publicados. O questionário permite uma avaliação do perfil empreendedor nos principais aspectos que o definem, como: busca de oportunidade e iniciativa, persistência, comprometimento, exigência de qualidade e eficiência, correr riscos calculados, estabelecimento de metas, busca de informações, planejamento e monitoramento sistemáticos, persuasão e rede de contatos, independência e autoconfiança. Além do que, o instrumento ainda conta com um fator de correção, que no caso do estudo se faz necessário à medida que o franqueado não gostaria de expor um perfil pouco empreendedor à franqueadora e sendo assim, poderia querer se supervalorizar. A análise das características empreendedoras e sua classificação numérica por característica mais marcante são fundamentais para que se possa estabelecer uma análise comparativa entre o perfil empreendedor e o desempenho do franqueado.

\section{METODOLOGIA}

O estudo foi realizado em empresas franqueadas de uma mesma rede de confecção infantil, localizadas em várias regiões do Brasil, com o objetivo de encontrar uma relação entre as características empreendedoras do franqueado e o desempenho da empresa franqueada. A estrutura deste estudo permitiu identificar as principais características dos empreendedores apontadas pela literatura e as características presentes nos franqueados do, por meio de um instrumento de coleta de dados. Analisou-se o desempenho das empresas franqueadas por meio de indicadores de desempenho utilizados pelas mesmas. $O$ instrumento de coleta de dados foi estruturado com perguntas fechadas em escala de Likert, e aplicado junto a população para identificar quais as características comportamentais dos franqueados de melhor desempenho.

A parte que buscava identificar as variáveis relativas ao desempenho organizacional foram coletadas por meio de análise documental, permitida pela empresa franqueadora. Este estudo caracterizou-se como uma pesquisa científica, pois possui procedimentos rigorosos. Primeiramente foi feita uma coleta de informações bibliográficas. Após a revisão 
da literatura e a formulação de uma fundamentação teórica, o instrumento de coleta de dados foi formulado em duas partes. Uma por meio de pesquisa documental em busca de informações sobre desempenho. A segunda parte foi feita por replicação do instrumento de mensuração desenvolvido por McClelland (1972) para CCEs - identificação das características comportamentais dos empreendedores. Como o isolamento de um fenômeno natural, a ser estudado, a mensuração das características comportamentais empreendedoras nos franqueados de uma rede de confecção infantil. Também tem características de enquête do tipo descritiva, método quantitativo e censitário. A pesquisa do tipo descritiva caracteriza-se como um estudo onde se pretende descrever as características de determinada população, ou estabelecer relação entre as variáveis. Richardson (1989, p. 91) sugere que a pesquisa descritiva tem o objetivo de “... descrever aspectos de uma população ou analisar a distribuição de determinadas características ou atributos". De acordo com Richardson (1989), o método quantitativo permite quantificar as informações coletadas, traduzir em números opiniões e informações para classificálas e analisá-las. Também permite interpretar os dados coletados, as características do comportamento empreendedor, o desempenho da empresa franqueada, relacionando-os através de diversas técnicas estatísticas. Para Gil (1987), os dados coletados por meio de levantamento possibilitam o agrupamento em tabelas, permitindo uma análise estatística, sendo as variáveis codificadas e correlacionadas.

A população pesquisada foi o conjunto de empresas franqueadas pertencentes a uma rede de confecção infantil, localizadas em diversos estados brasileiros. $\mathrm{O}$ universo considerado foi de 44 empresas franqueadas, $100 \%$ da população, caracterizando-se como uma pesquisa censitária, de acordo com Mattar (1996). As empresas franqueadas comercializam produtos de vestuário para o público infantil de ambos os sexos por meio de uma loja tematizada. Atende crianças de 0 a 12 anos com roupas, calçados e acessórios, distribuídos em duas marcas, uma feminina e outra masculina. Possuem um planejamento anual das ações de comunicação das marcas para o seu público alvo, os pais e familiares e para os usuários do produto, as crianças, através de clubes de consumidores. O questionário de McClelland (1972), estruturado e em uso pelo SEBRAE (2001), é composto por uma seqüência de 55 afirmações estruturadas de forma a identificar os dez comportamentos apontados pelo autor. As características comportamentais são: busca de oportunidades e iniciativa; persistência; comprometimento; exigência de qualidade e eficiência; correr riscos calculados; estabelecimento de metas; busca de informações; planejamento e monitoramento sistemático; persuasão e rede de contatos; independência e autoconfiança.

O instrumento de coleta de dados é composto por afirmativas que propõem uma auto reflexão do entrevistado, por meio de uma escala, que se fundamenta no raciocínio qualitativo de avaliações intangíveis de Likert. A pontuação da escala para cada afirmação, expressa o comportamento do entrevistado, considerando pontuação 1 , quando for equivalente a "nunca" ter tal comportamento, até o número 5 , que equivale "sempre" ter este comportamento. A pontuação final que identifica a intensidade de cada um dos dez comportamentos empreendedores foi feita através de uma tabela, que compreende uma seqüência estruturada de somas e subtrações, impedindo um raciocínio tendencioso do entrevistado. Mesmo que ocorra um tendenciamento do entrevistado para supervalorizar seus comportamentos, existe no instrumento, um fator de correção desenvolvido por McClelland (1972) , que serve como ponto de controle para pontuação final. O procedimento de coleta de dados foi realizado por meio do questionário auto-preenchível, já descrito no instrumento de coleta de dados. Os questionários foram entregues pessoalmente aos franqueados, sendo explicado a forma de preenchimento do mesmo. O método de coleta 
de dados, realizado por meio de questionário a ser preenchido pelos respondentes sem a presença do pesquisador foi factível, pois o material é simples, dando condições de ser auto-administrado. No entanto, dependerá da boa vontade dos respondentes, da sinceridade utilizada ao responder e de certa forma, se torna menos preciso. Utilizou-se para a análise de dados a estatística descritiva como a média para a identificação do perfil da população analisada. Análise simples comparativa foi necessária para identificar os perfis dos empreendedores com melhor desempenho nas organizações. Os mapas fatoriais determinaram as interdependências entre as variáveis analisadas.

Este estudo fica limitado aos franqueados da rede de confecção infantil pesquisada, não podendo ser extrapolado para outras redes de franquias sem estudo prévio. Deve-se considerar outra limitação deste estudo, a franqueza com que o respondente utilizou ao preencher o questionário, fato este alertado por Mattar (1986). A pesquisa limita-se a analisar as características comportamentais empreendedoras presentes nos franqueados que obtiveram um desempenho superior no seu negocio em relação aos demais. Portanto, os critérios de definição de desempenho superior se aplicam somente a esta rede de confecção infantil, não podendo ser comparando com outras redes do mesmo segmento, nem com redes de outros setores da economia, sem estudo prévio.

\section{RESULTADOS DA PESQUISA}

Esse capítulo esta dividido em três etapas, conforme os objetivos geral e específicos propostos neste trabalho. Na primeira etapa encontra-se a identificação das principais características comportamentais dos proprietários de franquias das empresas do ramos de confecção infantil. Estas características foram levantadas utilizando-se o instrumento de coleta de dados de McClelland (1972) e computadas em uma tabela de médias, a qual estabelece a característica predominante no grupo estudado. Na segunda etapa encontra-se o resumo das informações sobre desempenho das empresas franqueadas, demonstrada por uma tabela com índices individuais e desempenho geral perante a rede de franquias. Na terceira etapa identifica-se e compara-se as características comportamentais dos empresários, agrupando-os conforme seu desempenho. Esta análise é demonstrada através de mapas fatoriais elaborados com as características comportamentais e os respectivos índices de desempenho dos franqueados.

\section{a) Características comportamentais dos proprietários de franquias}

Com os resultados obtidos através do instrumento de coleta de dados e seu respectivo fator de correção, é possível resumir quais foram as características mais fortes entre os entrevistados. 


\section{TABELA 1 - CCEs - média geral}

\begin{tabular}{|ll|r|c|c|}
\hline \multicolumn{1}{|c|}{ CCEs } & média & máximo & mínimo \\
\hline 1 & Busca de oportunidades & 18,58 & 23 & 13 \\
\hline 2 & Persistência & 17,81 & 21 & 13 \\
\hline 3 & Comprometimento & 19,52 & 23 & 12 \\
\hline 4 & Exigência de qualidade e eficiência & 17,65 & 21 & 12 \\
\hline 5 & Correr riscos calculados & 16,81 & 20 & 13 \\
\hline 6 & Estabelecimento de metas & 20,87 & 25 & 16 \\
\hline 7 & Busca de informações & 19,32 & 25 & 14 \\
\hline 8 & Planejamento e monitoramento sistematico & 17,84 & 22 & 13 \\
\hline 9 & Persuasão e rede de contatos & 17,26 & 21 & 12 \\
\hline 10 & Independência e auto confiança & 18,29 & 25 & 14 \\
\hline
\end{tabular}

Esta análise torna-se importante na medida em que se busca saber qual a principal característica comportamental que rege o grupo estudado. Para isto, foi elaborada uma tabela de médias onde se pode verificar o perfil dos entrevistados.

O perfil empreendedor é atribuído ao individuo que atinge uma pontuação superior a quinze pontos, sendo assim pode-se dizer que, na média, o grupo estudado possui as características comportamentais do empreendedor, conforme McClelland (1992). Analisando-se a tabela de médias, nota-se que a característica comportamental mais predominante no grupo é o "estabelecimento de metas", seguido pelo "comprometimento" e "busca de informações". A característica comportamental "estabelecimento de metas" pode estar vinculada a forma de gestão da própria franqueadora, que exige fortemente a elaboração de metas e seu acompanhamento em todas as áreas de operação do negócio. A cultura do estabelecimento de metas encontra-se difundida desde o treinamento fornecido pela franqueadora até as normas e procedimentos descritos em manuais. A segunda característica de maior expressão é o "comprometimento". Neste caso também podemos relacionar o fato a uma realidade da franqueadora, pois um dos principais pontos de avaliação na seleção de candidatos a franquia é exatamente o comprometimento que o candidato terá com o futuro negócio. Este item é avaliado na seleção, não somente pelo tempo presente do franqueado à frente do negócio, mas também sobre a importância que o negócio terá em sua vida, ou seja, busca-se saber se a franquia não será apenas um hobbie ou passatempo para alguma pessoa que possua capital, pois são inúmeros os casos de esposas de empresários ou profissionais liberais que buscam uma franquia para ocupar o tempo ou se incluir na sociedade. A característica comportamental mais fraca do grupo foi "correr riscos". Pode-se interpretar este resultado simplesmente pelo fato do empresário haver escolhido uma franquia como negócio. Geralmente quando algum investidor escolhe uma franquia, opta por este modelo exatamente pelo fato do risco ser bem mais reduzido que de um negócio novo. Isto não quer dizer que o risco não exista, mas por ser um modelo já testado as chances de sucesso aumentam bastante, principalmente pelo apoio que receberá da franqueadora. As demais características expressadas pelas médias da tabela estão relativamente próximas umas das outras, existindo menos de dois pontos de diferença entre a maior e a menor. Estas médias estão alocadas entre 16,81 e 18,58, sendo que o perfil empreendedor é considerado presente a partir de quinze pontos e considerado altamente expressivo a partir de vinte pontos. Podemos dizer que em relação as demais características o grupo estudado possui um perfil empreendedor mediano. 


\section{b) Desempenho das empresas franqueadas}

O desempenho das empresas franqueadas foi levantado junto a empresa franqueadora e são referentes a média dos últimos doze meses de operação. Este período de avaliação foi considerado devido a característica do segmento de confecção, que tem como costume a analise dos resultados por coleção, sendo o ano dividido em duas grandes coleções, a de inverno e a de verão. Conforme informações fornecidas pela franqueadora, estas duas coleções possuem características muito distintas entre si devido a adequação das peças de vestuário ao fator climático, como também existe a influência da extensão do território nacional, que possui deferentes condições climáticas em um mesmo período do ano. A franqueadora atribuiu grande importância a este período de avaliação (12 meses), pois desta forma existe uma compensação entre os extremos climáticos do país, ou seja, enquanto o sul do país é beneficiado com as vendas da coleção de inverno, o nordeste será beneficiado com as vendas da coleção de verão. Sendo assim, existe um certo equilíbrio ou anulação de qualquer beneficio climático em relação as vendas. Portanto, dentro desta mesma orientação da empresa franqueadora, só foram analisadas as empresas com mais de um ano de operação. Deve-se ressaltar também que esta franquia é bastante recente, com apenas quatro anos de existência e que muitos processos ainda estão em fase de aprimoramento. Porém, mesmo sendo tão jovem, já ocupa a posição de liderança em volume de vendas e número de lojas franqueadas.

Os dados constantes na tabela a seguir são referentes aos índices de desempenho que a franqueadora utiliza para acompanhamento da evolução da rede de franquia. Nesta tabela constam os quatro índices de maior relevância para comparação do desempenho entre franqueados que são :

- faturamento: pontos percentuais de atingimento da meta proposta pela franqueadora para faturamento.

- faturamento por $\mathrm{m}^{2}$ : faturamento realizado dividido pela metragem da área de venda da respectiva loja.

- peças por atendimento: calculado dividindo-se o número de peças vendidas no mês pelo número de atendimentos realizados pelos vendedores da loja.

- valor por atendimento: foi calculado dividindo-se o faturamento realizado da loja pelo número de atendimentos realizados pelos vendedores.

- desempenho geral: índice utilizado pela empresa franqueadora para o estabelecimento de uma classificação de desempenho das lojas da rede. O índice de desempenho geral é calculado através de uma média simples dos índices individuais .

As empresas foram agrupadas em três intervalos. Utilizou-se o desempenho como o critério para a formação dos grupos sendo: 124,27 foi o maior índice obtido no desempenho geral e 72,99 foi o menor desempenho obtido. 
TABELA 2 - Agrupamento das empresas segundo seu desempenho

\begin{tabular}{|l|l|l|}
\hline Grupo & \multicolumn{2}{|l|}{ Intervalo de Desempenho } \\
\hline Desempenho superior & 124,27 (máximo) & 107,18 \\
\hline Desempenho médio & 107,18 & 90,09 \\
\hline Desempenho inferior & 90,09 & 73,20 (mínimo) \\
\hline
\end{tabular}

Os grupos foram formados subtraindo-se o menor índice do maior e dividindo-se por três, conforme demostra a tabela 4.

TABELA 3 - Indice de desempenho geral - superior

\begin{tabular}{|c|c|c|c|c|c|}
\hline \multicolumn{7}{|c|}{ Índice Geral de Desempenho } \\
\hline EMPRESA & Faturamento & Fatur./ $\mathrm{m}^{2}$ & Pç p/ Atend. & $\begin{array}{c}\text { Valor } \mathrm{p} / \\
\text { Atend. }\end{array}$ & $\begin{array}{c}\text { Desempenh } \\
\text { o Geral }\end{array}$ \\
\hline $\mathrm{U}$ & 96,31 & 123,80 & 115,45 & 112,41 & 111,99 \\
\hline $\mathrm{G}$ & 121,32 & 77,75 & 105,30 & 146,68 & 112,76 \\
\hline $\mathrm{P}$ & 82,96 & 52,93 & 150,76 & 175,42 & 115,52 \\
\hline $\mathrm{AP}$ & 123,31 & 150,60 & 90,22 & 122,07 & 121,55 \\
\hline $\mathrm{AB}$ & 121,38 & 126,31 & 107,76 & 141,63 & 124,27 \\
\hline
\end{tabular}

TABELA 4 - Análise das características comportamentais por agrupamento de desempenho geral

\begin{tabular}{|l|r|r|r|}
\hline \multicolumn{1}{|c|}{ Desempenho } & Inferior & Médio & Superior \\
\hline Busca de oportunidades & 18,10 & 19,5 & 19,75 \\
\hline Persistência & 18,35 & 17,17 & 17,25 \\
\hline Comprometimento & 19,65 & 19,17 & 20,00 \\
\hline Exigência de qualidade e eficiência & 17,55 & 17,33 & 20,00 \\
\hline Correr riscos calculados & 17,10 & 16,5 & 16,00 \\
\hline Estabelecimento de metas & 21,35 & 20,17 & 20,75 \\
\hline Busca de informações & 19,10 & 19,17 & 22,00 \\
\hline Planejamento e monitoramento sistemático & 17,40 & 17,83 & 20,25 \\
\hline Persuasão e rede de contatos & 17,55 & 15,67 & 19,00 \\
\hline Independência e auto confiança & 18,20 & 17,33 & 21,25 \\
\hline
\end{tabular}

c) Mapas fatoriais entre características comportamentais e desempenho geral e superior.

Para as variáveis Busca de oportunidades, Persistência, Comprometimento, Exigência de qualidade e eficiência, Correr riscos calculados, Estabelecimento de metas, Busca de informações, Planejamento e monitoramento sistemático, Persuasão e rede de contatos, Independência e auto-confiança. 


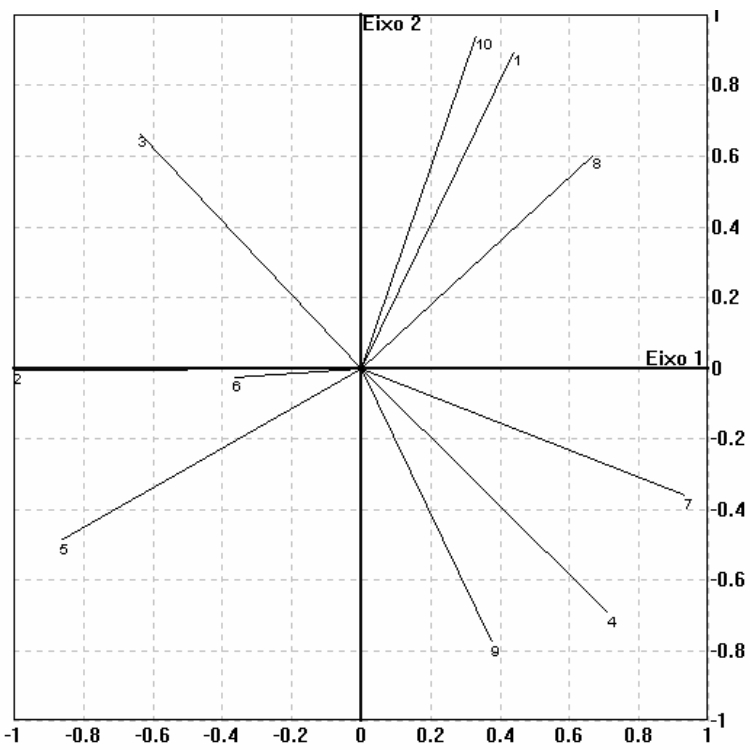

Figura 1 - Mapa fatorial dos franqueados de desempenho superior

No mapa fatorial dos franqueados de desempenho superior, nota-se que existem duas contraposições claras, a primeira, entre as características de comprometimento e exigência de qualidade e eficiência, a segunda, entre correr riscos calculados e planejamento e monitoramento sistemáticos. Na primeira contraposição pode-se estabelecer uma relação entre as duas características na medida em que a forte exigência por qualidade e eficiência por si só já trazem um comprometimento com o negócio, também podemos comprovar este raciocínio observando a tabela 3 sobre desempenho. Nesta tabela nota-se o alto grau e a semelhança de pontuação destas duas características. Na segunda contraposição nota-se, conforme tabela 3, que o grupo tende mais para a característica planejamento e monitoramento sistemático, com uma pontuação bastante alta, do que para correr riscos calculados, desta forma pode-se pensar que um forte planejamento diminui o risco a se correr.

De forma geral, analisando-se o mapa fatorial e o desempenho dos franqueados perante as características comportamentais, conforme tabela 3 , nota-se que este grupo possui pontuações altas em praticamente todas as características sendo as três mais fortes, por ordem, a busca de informações, estabelecimento de metas e independência e autoconfiança, sendo estas as características predominantes. Pode-se comentar que a busca de informação tem muita importância para o grupo e provavelmente foi o que regeu a opção do negócio e sua atual gestão. O estabelecimento de metas também se torna importante, à medida que este grupo busca o retorno do negócio. As características menos marcantes para este grupo foram, em ordem de importância, correr riscos calculados e persistência. Pode-se pensar, conforme comentado anteriormente, que a característica de correr riscos calculados pode ser um pouco anulada pela característica muito marcante do planejamento e monitoramento sistemáticos. No caso da característica persistência, acredita-se que a persistência não é uma característica tão marcante pelo fato que o grupo já conquista um resultado superior e de certa forma desenvolve outras características para dar continuidade aos resultados já conquistados. 


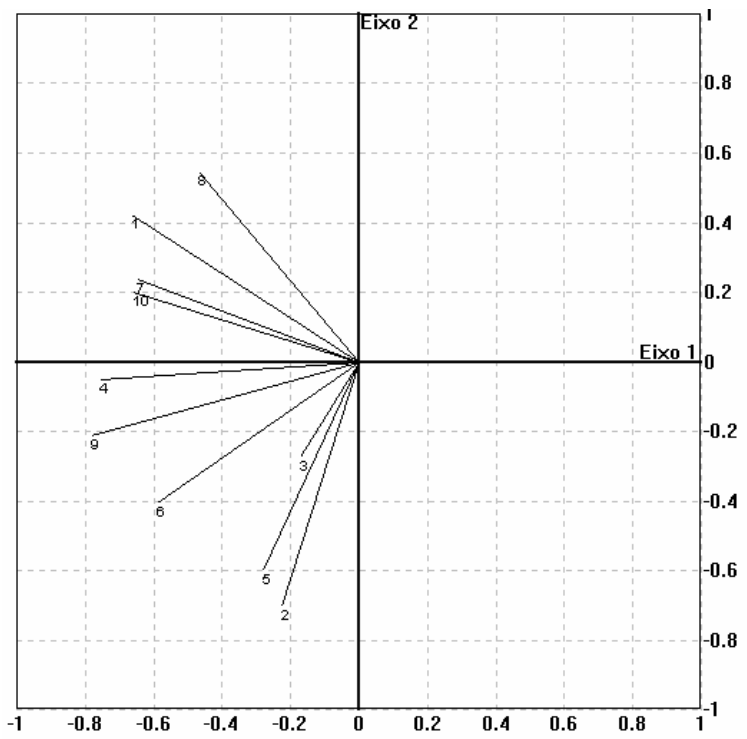

Figura 2 - Mapa fatorial geral dos franqueados

A segunda correlação se estabelece entre as características, persistência, comprometimento e correr riscos calculados Estas características o possuem uma média bem mais baixa, conforme tabela 3 , com exceção do comprometimento que tem uma pontuação média alta.

Avaliando-se a tabela 3 da média geral, percebe-se que existe uma diferença bastante significativa entre as médias mínimas e máximas, o que demonstra a grande diferença de perfis e características comportamentais no grupo estudado, o que tornou necessário o agrupamento por desempenho para possibilitar uma melhor análise. Por meio desta análise de dados observou-se que as empresas franqueadas pesquisadas que apresentaram o maior índice de características comportamentais empreendedoras foram também as que obtiveram os melhores resultados em desempenho. Sendo assim podese considerar que as características empreendedoras são um diferencial competitivo para um franqueado de confecção infantil da rede estudada.

\section{CONCLUSÕES E RECOMENDAÇÕES}

A aplicação desta pesquisa, demonstrou que os entrevistados, conforme a média geral, possuem o perfil empreendedor. Em seu estudo McClelland considera um empreendedor um indivíduo que, conforme questionário de mensuração, atinge uma pontuação superior a 15 pontos, sendo que o grupo atingiu uma média geral de 18,4 pontos, $22,7 \%$ acima do mínimo necessário. Pode-se então concluir que o grupo possui perfil empreendedor. Observou-se que os franqueados da rede de confecção infantil pesquisada possuem como característica mais desenvolvida o estabelecimento de metas, atingindo 20,8 pontos, sendo que esta característica está diretamente ligada a cultura da franquia em questão, que operacionalmente treina seus franqueados para o 
estabelecimento e cumprimento de metas. A menor média do grupo pesquisado estabeleceu-se na característica correr riscos calculados, com 16,81 de pontuação. Conforme esperava-se, segundo Leite (1998) e Longnecker et al (1997), alguns empresários que não querem correr tantos riscos ao abrir um novo empreendimento acabam iniciando uma franquia. $\mathrm{O}$ fato da escolha por este formato de negócio realmente minimiza o insucesso do empreendimento a medida que o modelo de negócio já foi previamente testado. As empresas pesquisadas foram agrupadas conforme seu desempenho, sendo divididas em três grupos, o de desempenho superior, o de desempenho médio e de desempenho inferior. Foi importante gerar este agrupamento para verificar o perfil dos gestores das empresas de melhor desempenho o que, conforme esperávamos, possuem as melhores médias gerais das características comportamentais comparando-se com os demais grupos.

As características empreendedoras mais marcantes no grupo de melhor desempenho foram, por ordem de importância: estabelecimento de metas em primeiro lugar; em segundo lugar, empatadas, as características planejamento e monitoramento sistemáticos, e independência e auto-confiança; também empatados, em terceiro lugar, comprometimento, exigência de qualidade e eficiência. Considerando-se que a maior pontuação possível de mensuração das CCEs, segundo instrumento desenvolvido por McClelland (1972), é de vinte e cinco pontos, sendo zero, o mínimo, as características citadas acima possuem médias superiores a vinte pontos no grupo de desempenho superior. As demais características se mantiveram acima de dezessete pontos, o que se considera uma pontuação média alta.

Pode-se afirmar que o alto valor apresentado para as CCEs e seu desempenho organizacional confirmam, por um lado, a confiabilidade do instrumento de coleta de dados, e por outro lado, aponta o perfil idealizado para os franqueados das empresas de confecção. Dentro deste mesmo raciocínio podemos concluir que o perfil empreendedor pode influenciar positivamente o resultado do negócio para a franquia estudada.

A franqueadora cada vez mais se dedica a seleção de candidatos à franquia, tendo em vista que o perfil do franqueado pode trazer grandes diferenças nos resultados a serem alcançados no negócio. Sendo assim, acredita-se que este estudo possa contribuir com as futuras seleções de candidatos, tendo em vista, a comprovação demonstrada sobre a diferença positiva de resultados atrelada ao grupo com características empreendedoras mais marcantes.

Torna-se claro que não se pode basear uma seleção de candidatos somente sobre um perfil empreendedor, como também não se pode afirmar que só por a pessoa possuir tal perfil terá sucesso no empreendimento proposto, mas pode-se concluir que as pessoas que possuem tais características poderão ter mais facilidade para alcançar melhores resultados. Considerando que a franqueadora investe no desenvolvimento de seus franqueados, desta forma estaria potencializando as chances de sucesso no novo negócio.

No perfil do empreendedor também existe a característica comprometimento e no grupo de desempenho superior, esta característica ficou classificada em terceiro lugar. Cita-se este posicionamento para abordar o tema parceria, que para o caso da franquia parece bem apropriado. A parceria neste caso ocorre principalmente na ação conjunta das duas partes, sendo que a franqueadora abastece o franqueado com normas, procedimentos e sugestões de gestão descritas em manuais. Por outro lado a franquia passa a ter uma relação de dependência e confiança nas diretrizes traçadas pela franqueadora. Sendo assim o perfil empreendedor fica um pouco tolhido, a medida que em diversas situações deverá obedecer os manuais. Desta forma o empreendedor deverá 
desenvolver e adaptar suas potencialidades dentro do contexto proposto e quase que se tornar um intra-empreendedor.

\subsection{RECOMENDAÇÕES}

Recomenda-se que novos estudos sejam realizados em outras redes de franquias similares, gerando comparativos e desta forma aprofundando o conhecimento sobre as características comportamentais de um empreendedor e sua relação com o desempenho do negócio. Desta forma será possível, em um futuro breve, estabelecer a descrição de um perfil "ideal" para futuros franqueados.

Às empresas franqueadoras recomenda-se que utilizem, em sua totalidade ou parcialmente, o instrumento de coleta de dados deste estudo para auxiliar no processo de seleção dos candidatos a franquia, pois conforme demonstrado, as empresaas franqueadas de melhor desempenho são administradas por empresários com maiores índices de características empreendedoras. Também recomenda-se à franqueadora da rede pesquisada que se utilize dos resultados apresentados neste estudo para desenvolvimento dos empresários que formam a rede, levantando-se os pontos fracos como tema de desenvolvimento de futuros treinamentos.

Aos franqueados disponibiliza-se esta pesquisa como fonte de estudo e aprimoramento, pois conhecendo-se os pontos fortes e fracos de suas características é possível traçar um plano de auto desenvolvimento na busca de melhores resultados.

\section{NOTAS}

${ }^{1}$ Henry Ford entendeu que seria possível produzir automóveis em massa, numa linha de montagem inédita e, definido um projeto básico e imutável, fundou a Ford.

${ }^{2}$ Franquia: concessão dada a alguém por uma companhia para comercializar seus produtos ou serviços.

\section{REFERÊNCIAS}

AZEVEDO, João Humberto de. Como iniciar uma empresa de sucesso. Rio de Janeiro: Qualitymark. 1992.

DEGEN, R. J. O empreendedor: fundamentos da iniciativa empresarial. São Paulo: McGraw-Hill, 1989.

DOLABELA, F. C. O segredo de Luísa: uma idéia, uma paixão e um plano de negócios: como nasce o empreendedor e se cria uma empresa. 13. São Paulo: Cultura, 2002.

Oficina do empreendedor. São Paulo: Cultura, 1999. 
DORNELAS, J. C. A. Empreendedorismo: transformando idéias em negócios. Rio de Janeiro: Campus, 2001.

DRUCKER, P. Inovação e espírito empreendedor: prática e princípios. São Paulo: Pinnia1991

A eficiência empresarial. Coleção Harvard de Administração. São Paulo: Nova Cultural, 1997.

FARREL, L. C. Entrepreneurship: fundamentos das organizações empreendedoras. São Paulo: Atlas, 1993.

FILION, L. J. Empreendedorismo: empreendedores e proprietários de pequenos negócios. Revista de Administração. São

Paulo, v. 34, n. 2, p. 5-28, abr.jun. 1999.

FUCS, J.; OSMAN, R. Como se tornar um vencedor nos negócios. Pequenas Empresas \& Grandes Negócios. São Paulo, n. 181, p. 38-49, fev. 2004.

FUCS, J. O construtor de idéias. Pequenas Empresas \& Grandes Negócios. São Paulo, n. 181, p. 34-36, fev. 2004.

GERBER, M. E. O mito do empreendedor: como fazer de seu empreendimento um negócio bem-sucedido. São Paulo: Saraiva, 1996.

KANITZ, S. O Brasil que dá certo. São Paulo: Makron Books, 1994.

KUTATKO, Donald F.; HODGETTS, Richard M. H. Entrepreneurship: a contemporary approach. Orlando: Dryden, 1989.

LEITE, R. C. De executivo a empresário: como realizar o seu ideal de segurança e independência. Rio de Janeiro: Campus, 1998.

LONGEN, M. T. Um modelo comportamental para o estudo do perfil do empreendedor. Florianópolis, 1997. Dissertação (Mestrado em Engenharia de Produção), Universidade Federal de Santa Catarina.

LONGENECKER J. G.; MOORE, C. W.; PETTY, J. William. Administração de pequenas empresas. São Paulo: Pearson Education do Brasil, 1997.

MATTAR, F. N. Pesquisa de marketing: metodologia, planejamento. São Paulo: Atlas, 1996.

MCCLELLAND, D. C. A sociedade competitiva: realização \& progresso social. Rio de Janeiro: Expressão e Cultura, 1972.

OLIVEIRA, M. A. (Org.). Valeu!: passos na trajetória de um empreendedor. São Paulo: Nobel, 1995.

PARENTE, J. Varejo no Brasil: gestão e estratégia. São Paulo:Atlas, 2000.

RICHARDSON, R. J. Pesquisa social: métodos e técnica. São Paulo: Atlas, 1989.

SÄ, A Lopes. Administração financeira: introdução a finanças de empresas. São Paulo: Atlas, 1969. 
SEBRAE - Serviço Brasileiro de Apoio às Micro e Pequenas Empresas. 2003: Percepção de novas oportunidades aumenta empreendedorismo no Brasil. Disponível em: www.sebrae.com.br/br/ued/download/MPMeExport1990a2000Funcex_outras.PDF. Acesso em 14 fev. 2003.

SCHNEIDER, A. A. (org) et al. Franchising: da prática à teoria. São Paulo: Maltese, 1991.

SEBRAE - Serviço Brasileiro de Apoio às Micro e Pequenas Empresas. 2003: Percepção de novas oportunidades aumenta empreendedorismo no Brasil. Disponível em: www.sebrae.com.br/br/ued/download/MPMeExport1990a2000Funcex_outras.PDF. Acesso em 14 fev. 2003.

TIMMONS, Jeffrey A. New venture creation: a guide to entrepreneurship. Illinois: Irwin, 1985.

TREUHERZ, Rolf Mario. Análise financeira por objetivos. São Paulo: Pioneira, 1999. ZOGHLIN, G. G. De executivo a empreendedor. São Paulo: Makron Books, 1994.

\title{
THE INFLUENCE OF ENTREPRENEURSHIP PROFILE ON THE BUSINESS PERFORMANCE OF AN INFANTILE GARMENT FRANCHISE NETWORK
}

\begin{abstract}
The objective of this study is to identify the main features of entrepreneurship behavior of the owners of an infantile garment franchise network and to examine how the entrepreneurship profile of the franchiser may influence the performance of the companies. Using descriptive and quantitative methodologies, we collected data of the performance of companies that belong to a franchise network in the sector of infantile garment and suggest an instrument for its evaluation. The results of the study showed that there is a correlation between a high level of performance and the presence of entrepreneurship qualities of the owners in the companies that have been analyzed. Thus, the results showed the importance of entrepreneurship features in the success of companies.
\end{abstract}

Key words: entrepreneurship, behavioral characteristics, franchise 